\title{
Analysis of the Behavior of a Turbomachine Driven by a Compressed Air System
}

\author{
Miguel Toledo-Velázquez ${ }^{1 *}$, Raúl Cruz-Vicencio ${ }^{2}$, Juan Abugaber-Francis ${ }^{1}$, \\ Juan Carlos Anzelmetti-Zaragoza ${ }^{2}$
}

\author{
${ }^{1}$ Instituto Politécnico Nacional, Escuela Superior de Ingeniería Mecánica y Eléctrica, Sección de Estudios de Posgrado e \\ Investigación, Laboratorio de Ingeniería Térmica e Hidráulica Aplicada (LABINTHAP), Unidad Profesional “Adolfo López \\ Mateos", Ciudad de México, México \\ ${ }^{2}$ Universidad Veracruzana, Escuela de Ingeniería Mecánica y Eléctrica, Unidad Poza Rica-Tuxpan, Veracruz, México \\ Email: *mtv49@yahoo.com
}

How to cite this paper: Toledo-Velázquez, M., Cruz-Vicencio, R., Abugaber-Francis, J. and Anzelmetti-Zaragoza, J.C. (2017) Analysis of the Behavior of a Turbomachine Driven by a Compressed Air System. Journal of Power and Energy Engineering, 5, 1-13.

https://doi.org/10.4236/jpee.2017.55001

Received: April 6, 2017

Accepted: May 21, 2017

Published: May 25, 2017

Copyright ( 2017 by authors and Scientific Research Publishing Inc. This work is licensed under the Creative Commons Attribution International License (CC BY 4.0).

http://creativecommons.org/licenses/by/4.0/

\begin{abstract}
Different experiments in high speed turbomachines require expensive and sophisticated infrastructure to implement their impulsion and reach high regimes. In developed countries, this can be achieved by using aeroderivative gas turbines or DC motors of about $400 \mathrm{HP}$. This paper presents an experimental system designed and built with the intention of performing behavior studies in test turbomachinery. The proposed installation uses compressed air as driving fluid, which allows the turbomachinery to reach high rotational speeds where very important phenomena occur. An analysis is carried out considering the rotational speed behavior of an internal combustion engine turbocharger of the Perkins series when it is driven by pressures ranging from $4.2 \mathrm{~kg} / \mathrm{cm}^{2}$ to zero. Additionally, another experiment couples an automotive electrical generator with the turbine to observe the system operation when a load is applied. The behavior of the pressure is analyzed when it is in function of the time of air discharge that goes from a compressed air storage tank to the turbocharger for its impulsion. This is an experimental system that can be designed and constructed economically within the bounds of any public university.
\end{abstract}

\section{Keywords}

Turbomachinery, Compressed air, Turbocharger, Vorticity

\section{Introduction}

When centrifugal compressors or high speed turbomachines are investigated, it 
is necessary to reach an appropriate range of operation to better understand the phenomena that take place at these regimes. One major problem is to have an adequate equipment to drive the turbomachines to such high rotational speeds. In developed countries, part of the research and development spending is intended for advanced and expensive infrastructure acquisition to carry out this type of experimentation.

The interest of experimenting with high speeds in turbomachinery is important because they work in normal operation and obtain their maximum efficiencies at these velocities [1].

Some papers such as [2] have studied the rotating stall and vibrations at high speeds. Here, experimental facility was used to analyze the vibrations of a centrifugal compressor which was driven by a DC motor between zero and 17,000 $\mathrm{rpm}$. To determine the operation curve of an experimental compressor, Arnulfi et al. [3] used a $400 \mathrm{HP}$ electric motor coupled with a speed-increaser gearbox to impulse the compressor. In [4], the driving was performed similarly but with a $500 \mathrm{~kW}$ engine. To analyze the vorticity phenomenon, Ellis [5] applied an experimental facility using a $15 \mathrm{HP}$ motor controlled by a set of pulleys regulating its speed; however, the experiment was performed at relatively low speeds between 1800 and $4000 \mathrm{rpm}$.

In general, the most mentioned methods in the literature are the impulsion though DC motors using powerful speed-increaser gearboxes and the method of aero derivative gas turbines.

This paper proposes a method to drive turbomachinery by using compressed air, highly ecological and that can be built with common mechanical elements of low cost. The propulsion system is under development and is used to analyze the behavior of a turbocharger based on the rotational speed and the flow through the turbine.

The paper is organized as follows: Section 2 includes the experimental infrastructure; Section 3 discusses the experimental method; Section 4 presents the mathematical model needed to perform the experiments; Section 5 gives an analysis of results; and Section 6 makes conclusions.

\section{Experimental Infrastructure}

The experimental system consists of two main parts: the compressed air supply system (Figure 1) and the turbomachine experimental test bed (Figure 2). The proposed compressed air system is described in more detail in [6] [7] and is a base infrastructure for other research projects.

The motor 1 with 15 HP drives the motor 2 that has been converted into a reciprocating compressor from a Volkswagen engine adaptation. The compressed air goes to the storage tank 3. After filling the tank, a valve directs the compressed air through the conduit 4 to the turbocharger suction 5 . The air causes the rotation of the turbine causing the discharge of the centrifugal compressor through the pipe 6 . The oscilloscope 7 is used to measure the rotational speed of the turbocharger. In this way, the turbocharger is the object of study. 


\section{Experimental Method}

As mentioned before, an analysis is performed considering the behavior of the rotational speed of an internal combustion engine turbocharger of the Perkins series (Figures 3-5) when it is impelled by pressures going from $4.2 \mathrm{~kg} / \mathrm{cm}^{2}$ to 0 . These pressures are possible due to the compressed air stored in a receiver tank [8] [9]. Figure 6 illustrates the experimental installation.

The electric motor drives the compressor compressed air to a pressure of 4.2 $\mathrm{kg} / \mathrm{cm}^{2}$. Then, the valve is opened to let the air impulse the turbocharger gradually through subsonic flow velocities which are measured by an electronic circuit based on an optoelectronic sensor as shown in Figure 7.

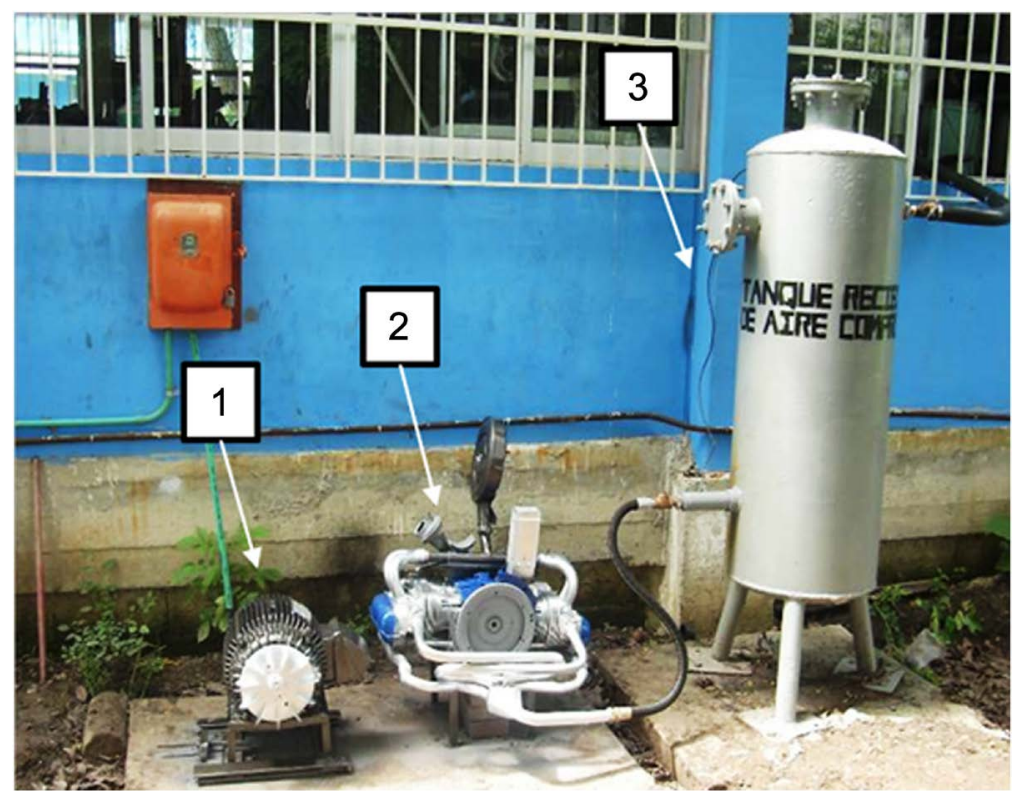

Figure 1. Compressed air supply system.

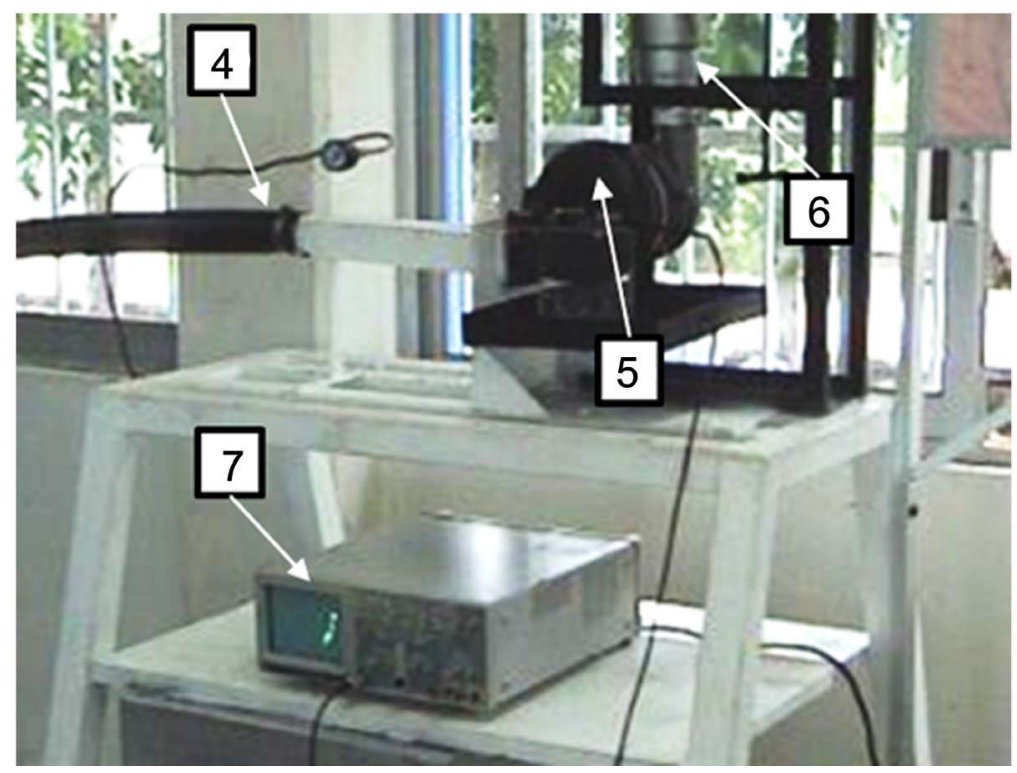

Figure 2. Experimental test bed. 


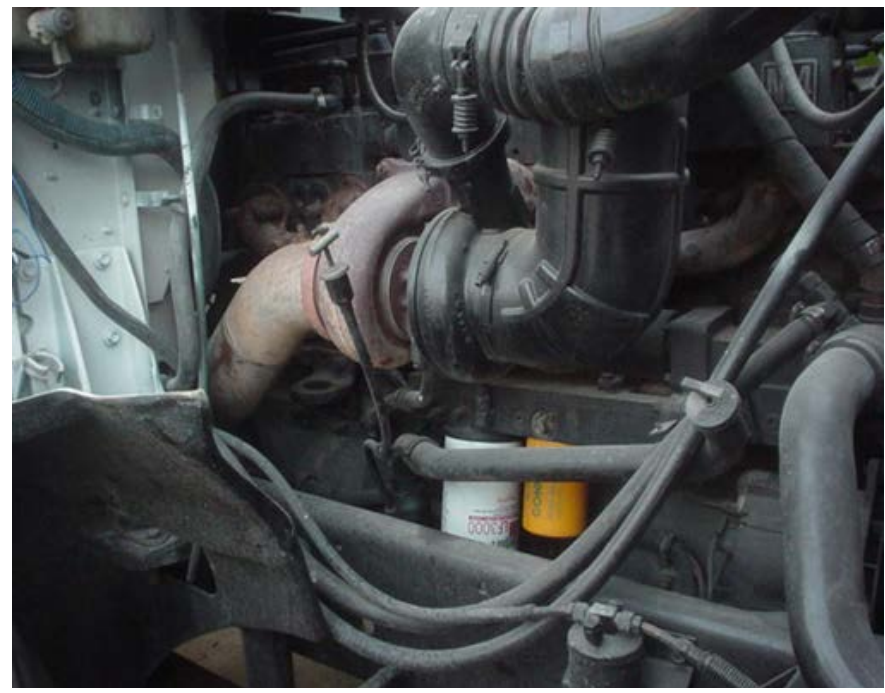

Figure 3. Turbocharger installed.

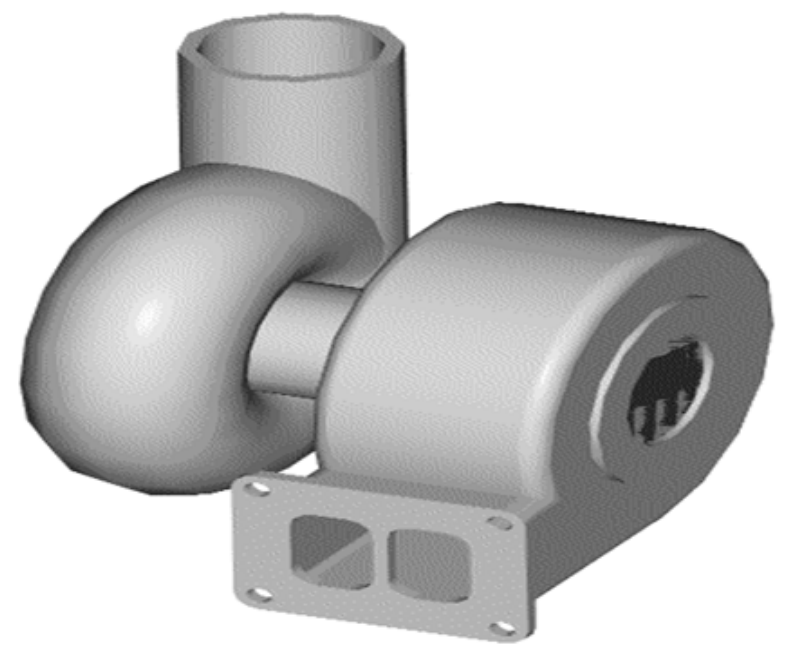

Figure 4. Example of a simulated turbocharger.

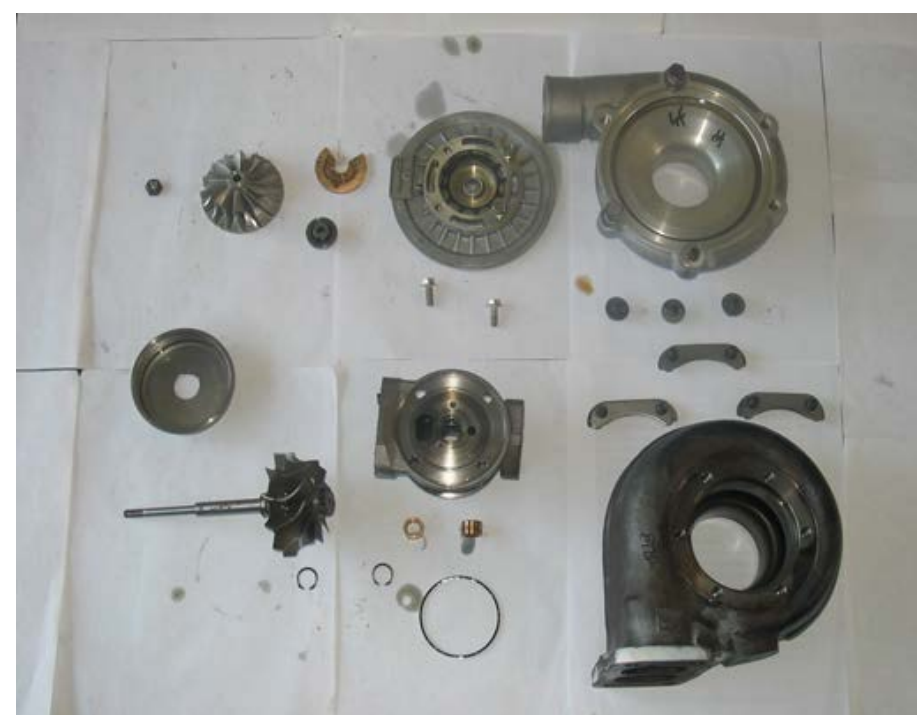

Figure 5. Components of a turbocharger. 


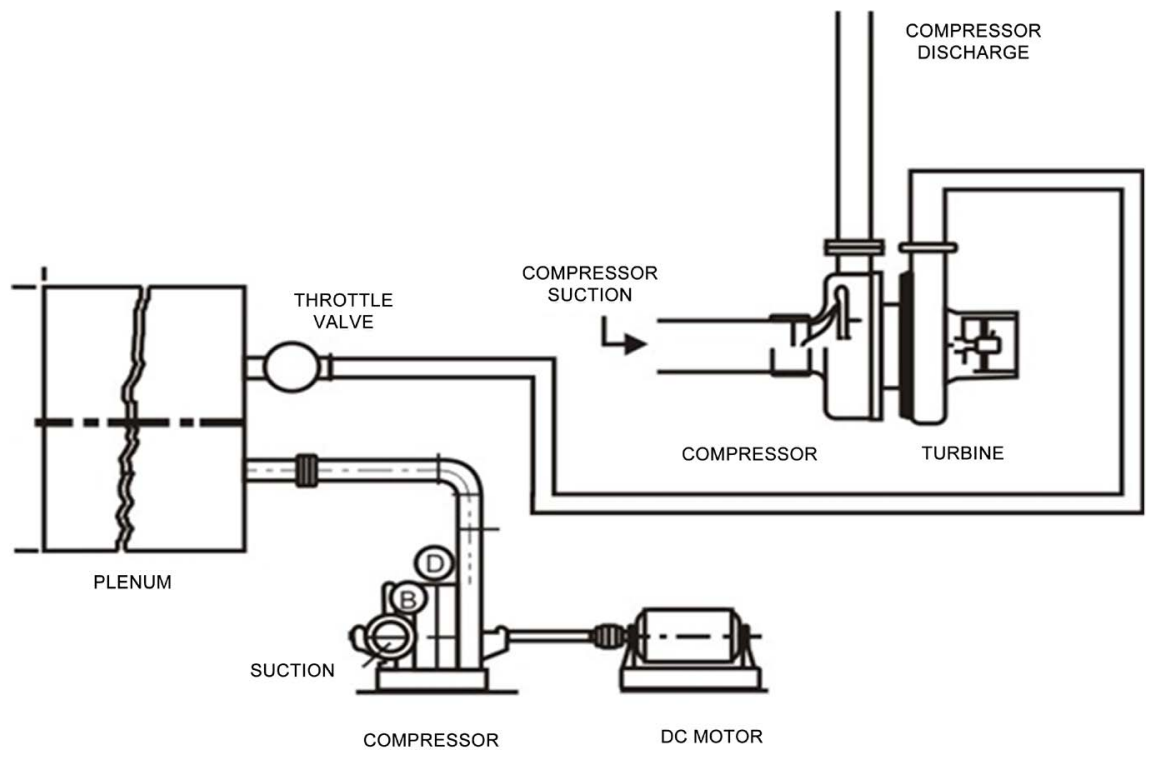

Figure 6. Experimental installation.

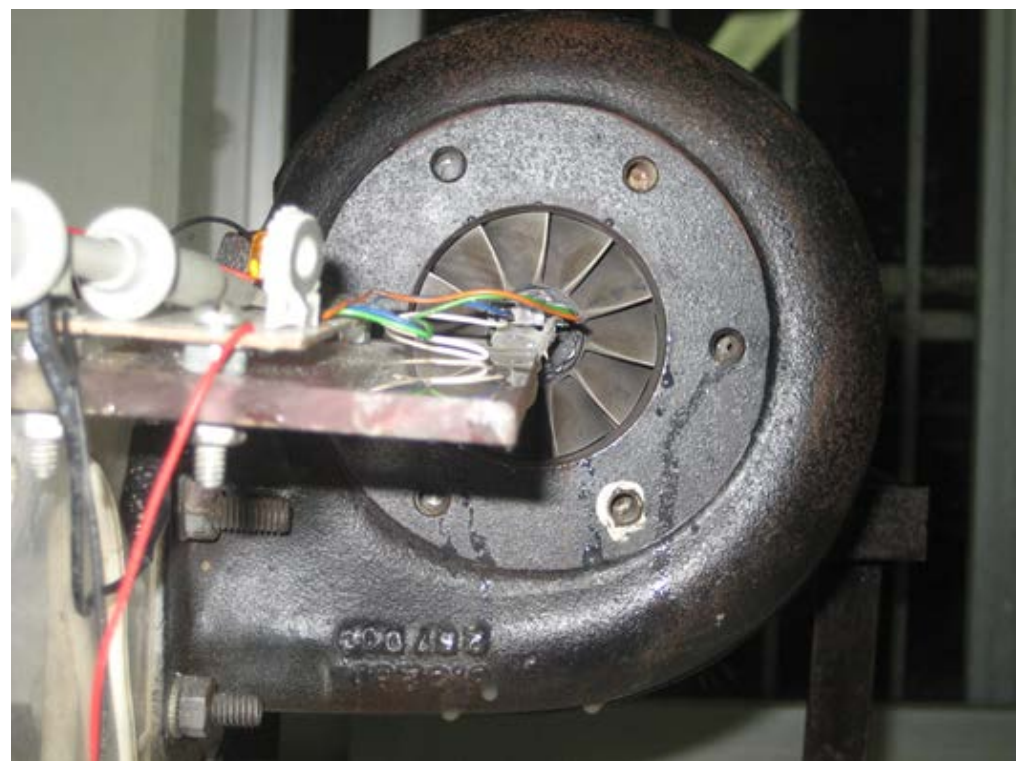

Figure 7. Electronic circuit for detecting rotational speeds.

The electronic signal is detected and sent to an oscilloscope (Figure 8) which is used to measure the period and the frequency and determine the rpm of the turbomachine.

From repeated experiments, different velocities are obtained as a function of the time of air discharge from the tank. Figure 9 illustrates this behavior.

Then, the turbine is coupled with an automotive electric generator in order to observe the system operation when a load is applied. The compressor section is separated from the turbocharger and the automotive electric generator is installed instead. This is intended for a part of a process that involves preliminary tests and allows the system to work with commercial electric generator in the future. Figure 10 shows the coupling between generator and turbine. 
Some tests are carried out analyzing the gauge pressure behavior in the tank when it is function of the time of discharge (Figure 11).

\section{Mathematical Model}

After obtaining the experimental installation operation, the theory of gas dynamics is applied to analyze this behavior [10]. To simplify the analysis it is assumed that the storage tank discharge process is an isentropic process from a gauge pressure of $3.2 \mathrm{~kg} / \mathrm{cm}^{2}$ to atmospheric pressure. Therefore this process can be compared to the same that occurs in an isentropic flow through a convergent reduction as can be illustrated in Figure 12. In this figure, the turbine air discharge $\mathrm{A}$ is at atmospheric conditions, thus it is feasible to simulate the pipe and the turbine by a length equivalent to a convergent nozzle with cross-section $\mathrm{A}$. This assumption is made in order to obtain the flow behavior in the discharge period through the turbine when the compressor replaced by generator.

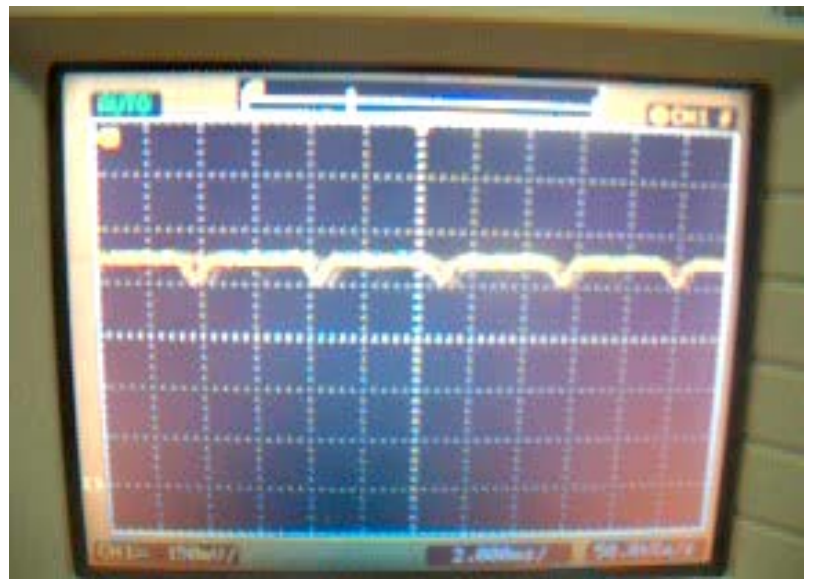

Figure 8. Signal obtained from the electronic circuit.

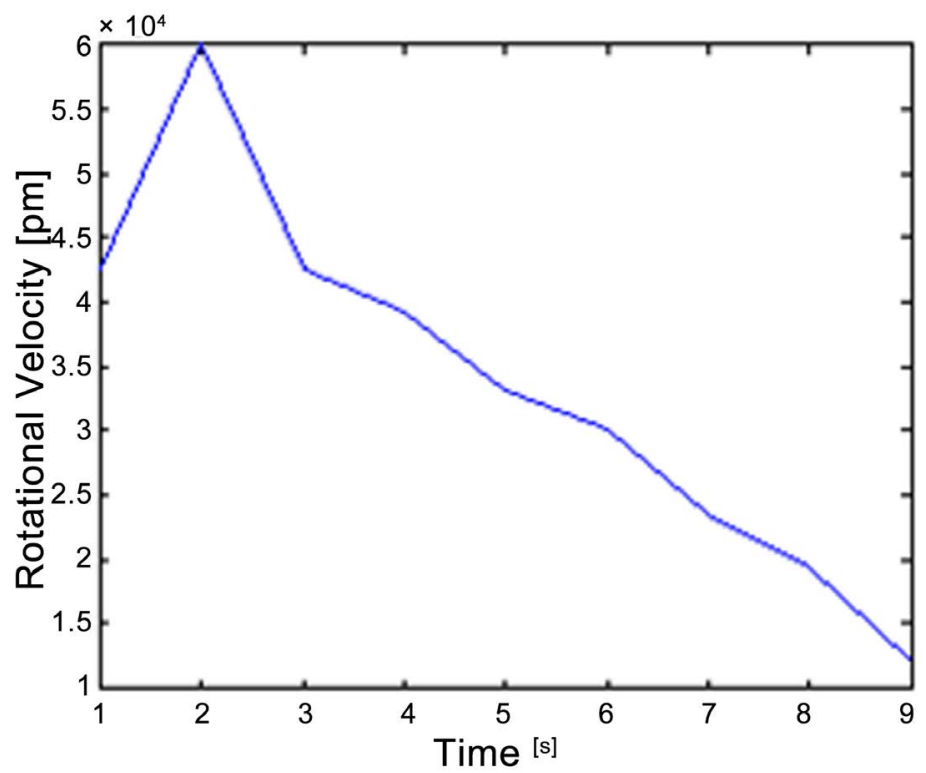

Figure 9. Behavior of the rotational speed. 


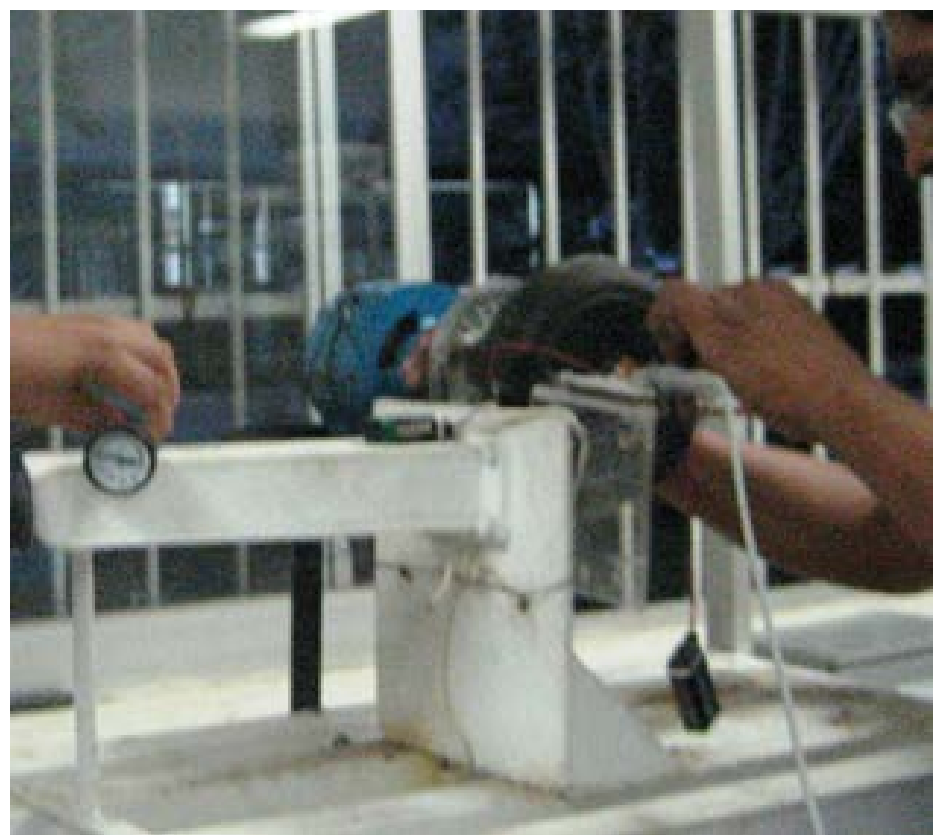

Figure 10. Generator coupled to the turbine.

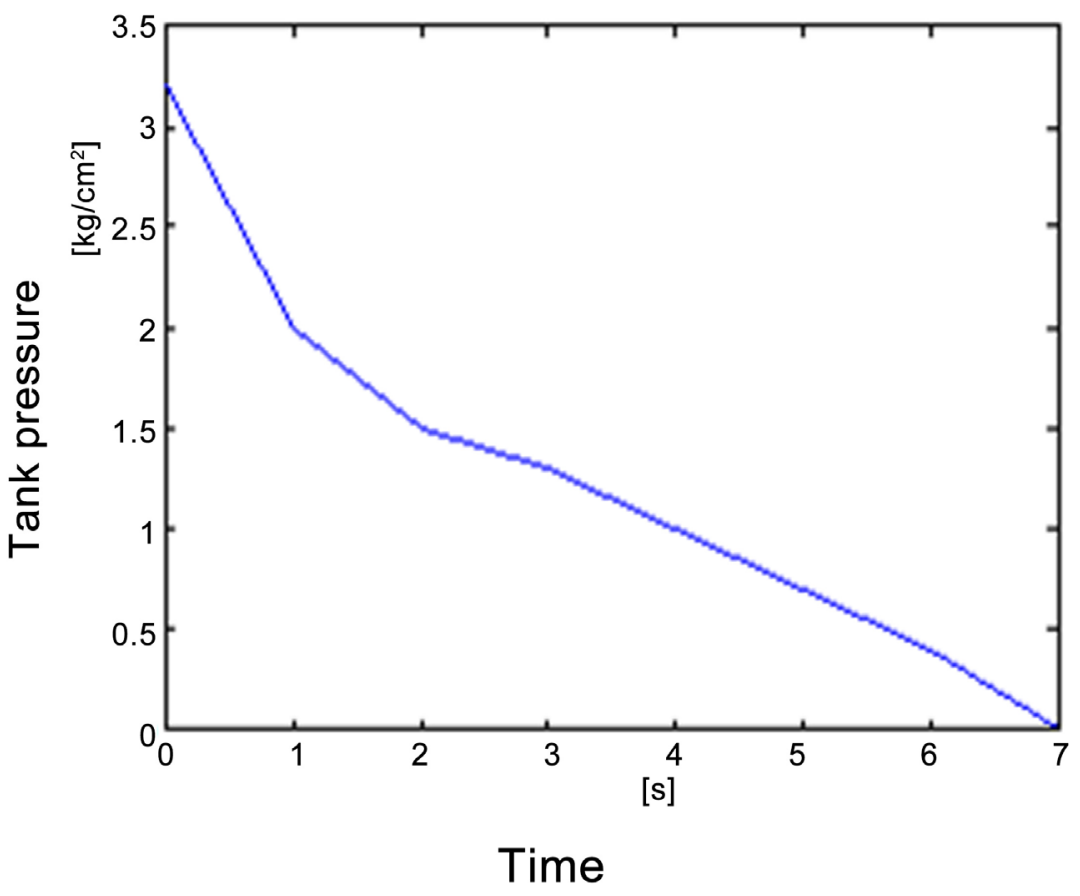

Figure 11. Pressure behavior when load is applied.

Let us consider $\mathrm{P}_{\mathrm{o}}, \mathrm{T}_{\mathrm{o}}, \rho_{\mathrm{o}}$, the absolute pressure, the temperature and density corresponding to the air tank and $\mathrm{P}, \mathrm{T}, \rho$ the corresponding magnitudes in the equivalent convergent nozzle that replaces turbine and the pipe in the experiment system. The flow phenomenon is described as:

$$
p_{o}=p\left(1-\frac{\gamma-1}{2} M^{2}\right)^{\frac{\gamma}{\gamma-1}}
$$


where $p_{\mathrm{o}}$ is the pressure in the tank, $p$ is the pressure in the nozzle, $M$ is the Mach number of the flow and $\gamma$ the ratio of specific heats (in this case air with value of 1.4). Considering that for a sonic flow $M=1$ and Equation (1), we have:

$$
P_{o} / p=1.89
$$

Equation (2) is the critical pressure ratio. When this ratio is greater than or equal to 1.89 , then the flow is sonic and is calculated using the critical magnitudes $T_{c}$ and $\rho_{c}$. The present study was performed in the city of Poza Rica, Veracruz with an atmospheric pressure of $100 \mathrm{kPa}$ and a temperature of $30^{\circ} \mathrm{C}$. From Equation (2), it is deduced that the flow reaches the speed of sound for tank pressures higher than $189 \mathrm{kPa}$. In this case, the measured superior pressure is 420 $\mathrm{kPa}$, thus the flow reaches the speed of sound in the range of $420-189 \mathrm{kPa}$. Less than $189 \mathrm{kPa}$, the flow is subsonic and is calculated differently.

The next step is to calculate the mass flow for sonic and subsonic intervals. During the experiment, the tank temperature To is considered to be always constant with value of $30^{\circ} \mathrm{C}$, the ratio of specific heats $\gamma=1.4$ and $\mathrm{R}=287 \mathrm{~J} / \mathrm{kg} \mathrm{K}$. Table 1 presents the values corresponding to mass flow obtained in the sonic flow range between 0 and 4 seconds that is the time interval in which flow moves at the speed of sound. To form the table, the following equations are used:

$$
\begin{aligned}
& T_{c}=0.8337 T_{0} \\
& \rho_{o}=\frac{P_{0}}{1.89 R T_{c}}
\end{aligned}
$$
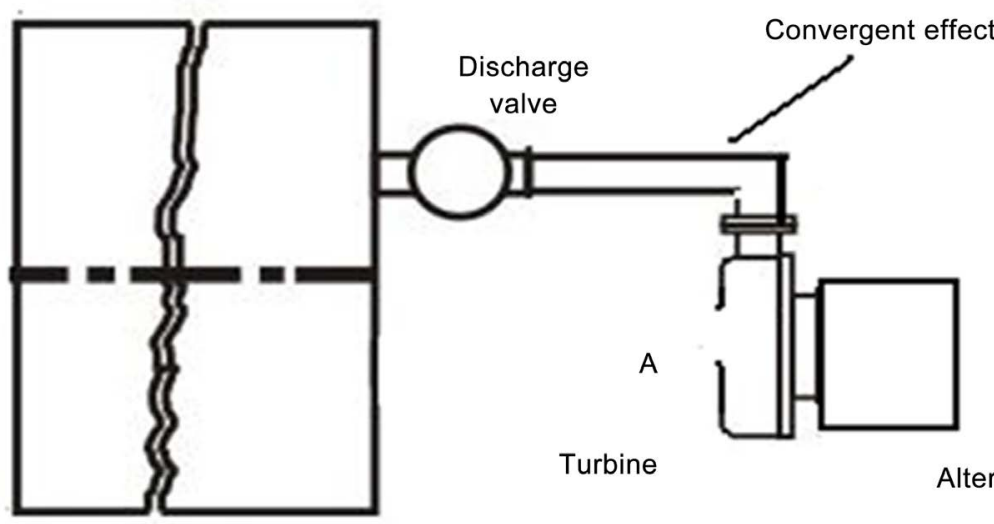

Turbine

Alternator

Air tank

Figure 12. Storage tank discharge through a convergent pipe.

Table 1. Mass flow for the sonic interval.

\begin{tabular}{ccccccc}
\hline Tiempo $(\mathrm{s})$ & $P_{0}(\mathrm{kPa})$ & $P_{\mathrm{o}} / p$ & $T_{c}(\mathrm{~K})$ & $\rho_{c}\left(\mathrm{~kg} / \mathrm{m}^{3}\right)$ & $a=V(\mathrm{~m} / \mathrm{s})$ & Flow $(\mathrm{kg} / \mathrm{s})$ \\
\hline 0 & 420 & 4.2 & 252.6 & 3.06 & 318.5 & 0.39 \\
1 & 300 & 3.2 & 252.6 & 2.19 & 318.5 & 0.28 \\
2 & 250 & 2.5 & 252.6 & 1.82 & 318.5 & 0.23 \\
3 & 230 & 2.3 & 252.6 & 1.67 & 318.5 & 0.21 \\
4 & 200 & 2 & 252.6 & 1.46 & 318.5 & 0.18 \\
\hline
\end{tabular}




$$
\begin{aligned}
& a=\sqrt{\gamma R T_{c}} \\
& \dot{m}=a \rho_{c} A
\end{aligned}
$$

Table 2 shows the values of mass flow obtained for the range between 5 and 7 seconds that is the time interval in which flow moves at the subsonic speed. This behavior is verified at pressures lower than $186 \mathrm{kPa}$.

The following equations are used to form the table:

$$
\begin{gathered}
T=T_{0}\left(\frac{P}{P_{0}}\right)^{0.2857} \\
\rho=\frac{P}{R T} \\
a=\sqrt{\gamma R T_{c}} \\
v=2.236 a \sqrt{\left(\frac{P_{0}}{P}\right)^{0.2857}-1}
\end{gathered}
$$

The effective area $\mathrm{A}$ is considered to be $4 \mathrm{~cm}^{2}$ and is an approximation to the area over which the air makes contact with the turbine inlet. In Figure 13, the mass flow is plotted against the time of air discharge shown in Table 1 and Table 2. Figure 14 illustrates the sudden change of behavior when there is a transition of flow regime from sonic to subsonic in the range between 4 and 5 seconds after the tank discharge.

If the tank volume $\mathrm{V}_{0}$ is used as control volume, the equation of state can be applied as:

$$
P=\frac{m}{V_{0}} R T_{0}
$$

The derivative of Equation (11) results in a function of the mass flow:

$$
\frac{\mathrm{d} P}{\mathrm{~d} t}=\frac{\mathrm{d} m}{\mathrm{~d} t}\left(\frac{R T_{0}}{V_{0}}\right)
$$

Using the corresponding constant values and $\mathrm{V}_{\mathrm{o}}=0.34 \mathrm{~m}^{3}$, we obtain:

$$
\frac{\mathrm{d} m}{\mathrm{~d} t}=\frac{\frac{\mathrm{d} P}{\mathrm{~d} t}}{255767}
$$

To calculate $\mathrm{dP} / \mathrm{dt}$ at each point of Figure 11, numerical methods based on finite differences are used. Table 3 shows there results.

The behavior of the mass flow can be obtained in the same manner for the second method. Figure 15 shows the comparison of both results for the mass flow using the procedures mentioned.

Table 2. Mass flow for the subsonic interval.

\begin{tabular}{ccccccc}
\hline $\begin{array}{c}\text { Tiempo } \\
(\mathrm{s})\end{array}$ & $\begin{array}{c}P_{0} \\
(\mathrm{Kpa})\end{array}$ & $P_{\mathrm{o}} / p$ & $\begin{array}{c}T \\
(\mathrm{~K})\end{array}$ & $\begin{array}{c}\rho \\
\left(\mathrm{kg} / \mathrm{m}^{3}\right)\end{array}$ & $\begin{array}{c}V \\
(\mathrm{~m} / \mathrm{s})\end{array}$ & $\begin{array}{c}\text { Flujo } \\
(\mathrm{kg} / \mathrm{s})\end{array}$ \\
\hline 5 & 170 & 1.7 & 260.3 & 2.27 & 292.5 & 0.26 \\
6 & 140 & 1.4 & 275 & 1.77 & 235 & 0.16 \\
7 & 0 & 1 & 303 & 1.14 & 0 & 0 \\
\hline
\end{tabular}




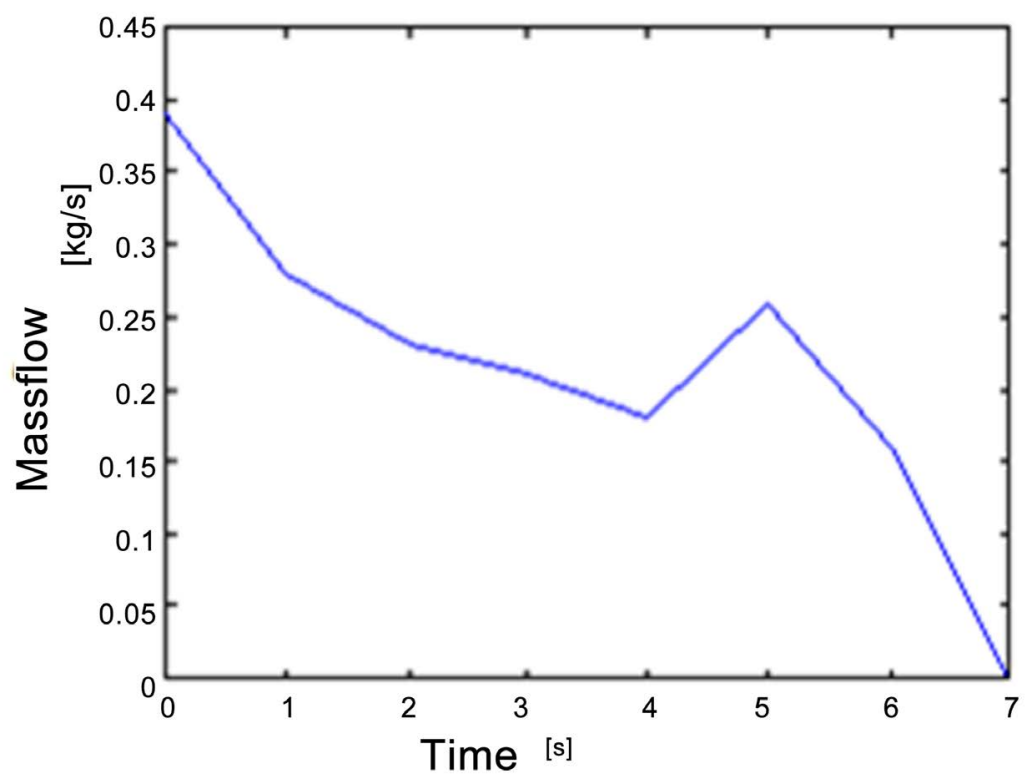

Figure 13. Behavior of the mass flow.

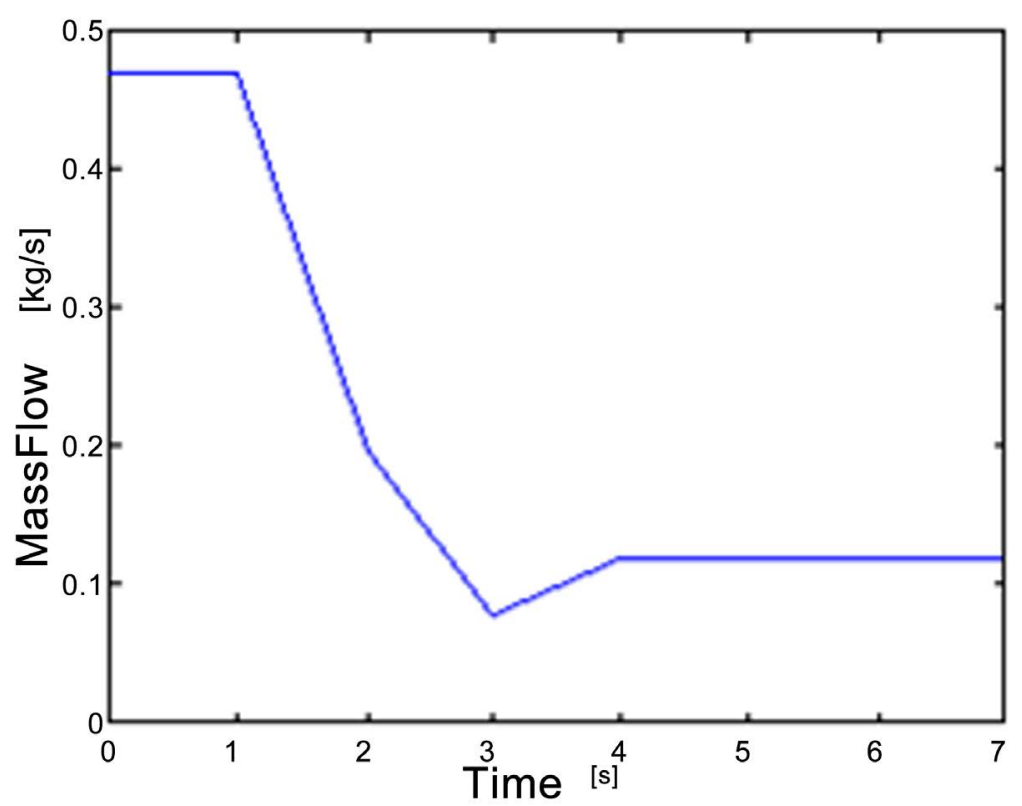

Figure 14. Behavior of the mass flow using the volume control located in the tank.

Table 3. Mass flow behavior using the control volume located in the tank.

\begin{tabular}{ccc}
\hline Tiempo $(\mathrm{s})$ & $\mathrm{dP} / \mathrm{dt}$ & $\mathrm{dm} / \mathrm{dt}$ \\
\hline 0 & 120000 & 0.47 \\
1 & 120000 & 0.47 \\
2 & 50000 & 0.195 \\
3 & 20000 & 0.078 \\
4 & 30000 & 0.12 \\
5 & 30000 & 0.12 \\
6 & 30000 & 0.12 \\
7 & 30000 & 0.12 \\
\hline
\end{tabular}




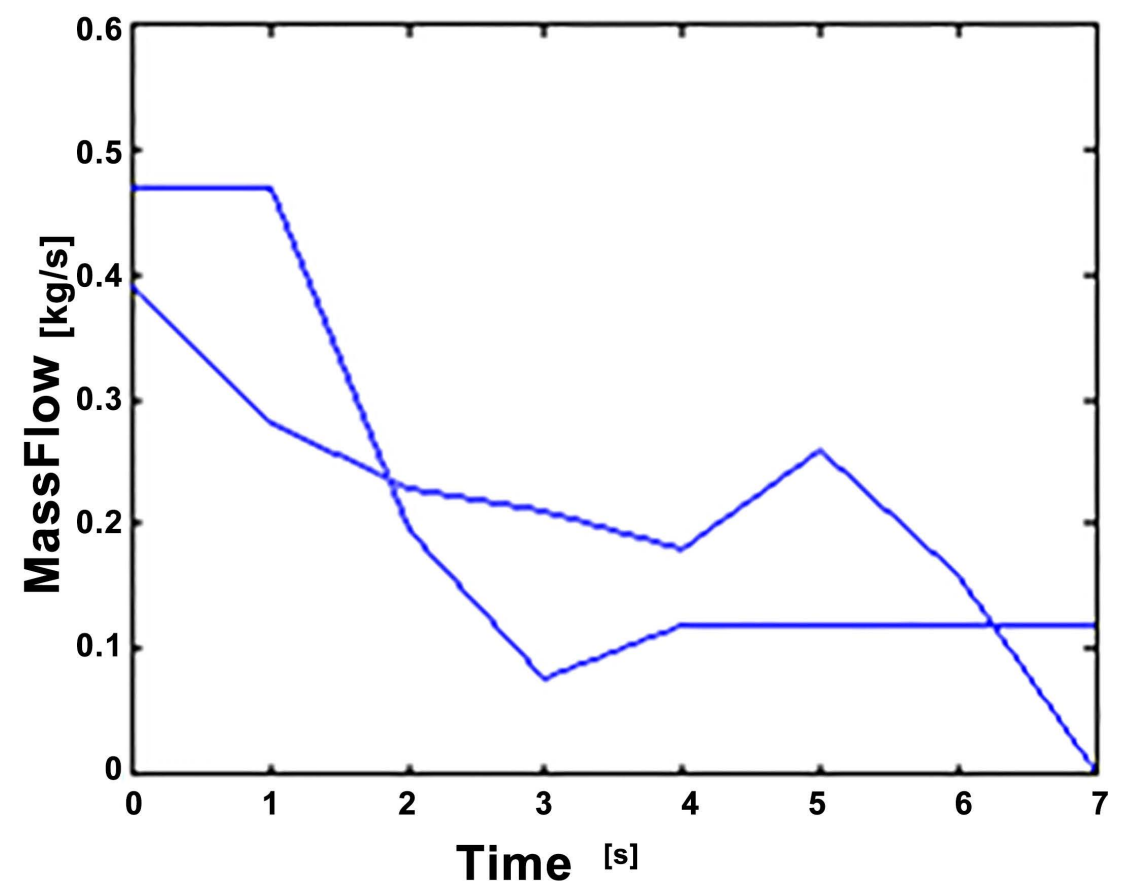

Figure 15. Comparison between the two analyzes.

This comparison suggests the use of an estimated behavior which is defined by the graph that lies between the two curves obtained mathematically. Opting for an average of these two graphs which perhaps will respond in a more consistent manner for the actual mass flow and take into account the effects of fluid compressibility induced in both subsonic and sonic regimes.

\section{Analysis of Results}

The first experiment that used the turbocharger Perkins, showed its transient behavior defined by Figure 9. According to the figure, it is possible to reach speeds relatively high, which are necessary to implement an appropriate analysis in high speed turbomachinery. As can be seen, there exist a convenient regime between 42,000 and 60,000 rpm. In this case, this interval speed behavior can be used when studies of its centrifugal compressor are required. In order to obtain larger time intervals and higher speeds, it is necessary to increase the tank pressure and adapt regulators to maintain the compressor speed constant and conduct an adequate characterization.

The second experiment replaced the centrifugal compressor from the turbocharger and an automotive electric generator was coupled to the turbine instead. Its discharge pressure behavior curve was shown in Figure 11. Analyzing the mass flow, using the compressed air tank contour as control volume and considering Equation 12, it is visible that the transient behavior of pressure is proportional to the behavior of the instantaneous flow mass and if discontinuities in the transient mass flow are not considered, then it is proportional to the slope of the tangent at each point from Figure 11, obtaining a behavior as Figure 14.

However, when the effects derived from the compressibility of air are consi- 
dered, the flow behavior with respect to time has a different tendency caused by the transition effect from supersonic to subsonic flow in the discharge period of the deposit.

It can be inferred from this result that there is a range of operation for the turbomachinery, limited by the two curves shown in Figure 15. There is evidence that the behavior obtained is plausible under these conditions. In a future experiment, the hypothesis can be checked by using adequate instrumentation in order to limit the enunciation of the results.

\section{Conclusions}

According to the results we can obtain the following conclusions:

- Using the experimental setup based on a system of compressed air supply and the experimental test-bed described in this paper, it is possible to carry out tests in high speed rotating turbomachinery.

- In the case of the turbocharger Perkins that was used in this experiment, it is possible to work with speeds between 15,000 and 60,000 rpm. Also, it is possible to obtain the compressor performance curves, as long as the adequate instrumentation is available.

- According to the proposed mathematical analysis in this work, a gap of operation for the instantaneous mass flow is deduced in the range of the experimental time.

- One proposal is to obtain an average curve between the two shown in Figure 15 , defining the behavior of the given mass flow of fluid compressibility effects and shockwaves.

- This experimental equipment can be configured to perform studies in centrifugal compressors.

- Usually the drive systems for high speed turbomachinery are expensive; however, the system presented in this work can be built at low cost, with a budget within the bounds of any public university.

\section{Acknowledgements}

This work was carried out with the support of the University of Veracruz and the National Polytechnic Institute of Mexico.

\section{References}

[1] Rodgers, C. (1964) Typical Performance Characteristics of Gas Turbine Radial Compressors. Journal of Engineering for Power, 86, 161-170.

[2] Bently, D.E. and Goldman, P. (2000) Vibrational Diagnostics of Rotating Stall in Centrifugal Compressors. ORBIT, 21, 46-50.

[3] Arnulfi, G.L., Giannattasio, P., Giusto, C., Massardo, A.F., Micheli, D. and Pinamonti, P. (1999) Multistage Centrifugal Compressor Surge Analysis: Part I-Experimental Investigation. Journal of Turbomachinery, 121, 305-311. https://doi.org/10.1115/1.2841315

[4] Justen F., Ziegler K. and Gallus H. (1999) Experimental Investigation of Unsteady Flow Phenomena in a Centrifugal Compressor Vaned Diffuser of Variable Geome- 
try. Journal of Turbomachinery, 121, 763-771. https://doi.org/10.1115/1.2836730

[5] Ellis, G.O. (1964) A Study of Induced Vorticity in Centrifugal Compressors. ASME Journal of Engineering for Power, 86, 63-76. https://doi.org/10.1115/1.3675420

[6] Juárez, J., Martínez, M. and Zarate, R. (2004) Diseño y construcción de banco experimental de pruebas para la determinación del comportamiento de un compresor centrífugo. Undergraduate Thesis, University of Veracruz, Veracruz.

[7] Cruz, R. (1998) Análisis Teórico y Numérico del Flujo en el Impulsor de Compresores Centrífugos. Master's Thesis, National Polytechnic Institute, Ciudad de México.

[8] Goldstein, A.W. (1948) Design and Performance of Experimental Axial-Discharge Mixed-Flow Compressor: I-Impeller Design Theory. NACA-RM-E8F04.

[9] Came, P.M. (1978) The Development, Application and Experimental Evaluation of a Design Procedure for Centrifugal Compressors. Proceedings of the Institution of Mechanical Engineers, 192, 49-67. https://doi.org/10.1243/PIME_PROC_1978_192_007_02

[10] Toledo, M. and Cruz, R. (2003) Polytropic Analysis of a Centrifugal Compressor. Información Tecnológica, 14, 9-14.

Submit or recommend next manuscript to SCIRP and we will provide best service for you:

Accepting pre-submission inquiries through Email, Facebook, LinkedIn, Twitter, etc. A wide selection of journals (inclusive of 9 subjects, more than 200 journals) Providing 24-hour high-quality service User-friendly online submission system Fair and swift peer-review system Efficient typesetting and proofreading procedure Display of the result of downloads and visits, as well as the number of cited articles Maximum dissemination of your research work

Submit your manuscript at: http://papersubmission.scirp.org/

Or contact jpee@scirp.org 